\title{
Olive Leaf Extract as a Corrosion Inhibitor of Carbon Steel in $\mathrm{CO}_{2}$-Saturated Chloride-Carbonate Solution
}

\author{
Gordana Pustaj ${ }^{1, *}$, Frankica Kapor $^{1}$, Želimir Veinovic ${ }^{2}$ \\ ${ }^{1}$ Department of Chemistry, Faculty of Mining Geology and Petroleum Engineering, Zagreb, Croatia \\ ${ }^{2}$ Mining and Geotechnical Engineering Department, Faculty of Mining Geology and Petroleum \\ Engineering, Zagreb, Croatia \\ *E-mail: gordana.pustaj@rgn.hr
}

doi: $10.20964 / 2016.09 .25$

Received: 2 May 2016 / Accepted: 24 May 2016 / Published: 7 August 2016

In the present study corrosion inhibition of carbon steel in $\mathrm{CO}_{2}$-saturated chloride-carbonate solution by the olive leaf extract has been researched. For that purpose the electrochemical and spectrophotometric techniques such as potentiodynamic polarization, electrochemical impedance spectroscopy and Fourier transform infrared spectroscopy were employed. Both electrochemical techniques, potentiodynamic polarization and electrochemical impedance spectroscopy, demonstrate that olive leaf extract inhibits the carbon steel corrosion in $\mathrm{CO}_{2}$-saturated chloride-carbonate solution. It was determined that the inhibition efficiency increases with increasing concentration of the olive leaf extract. The olive leaf extract achieves high corrosion efficiency as a mixed type inhibitor, with a prevailing influence on the anode process. Recorded electrochemical impedance spectra in the presence of the extract show the presence of the inhibitor film on the steel surface. This is further confirmed by the recording in Fourier transform infrared spectroscopy spectrum.

Keywords: Carbon steel; $\mathrm{CO}_{2}$ corrosion; Inhibitor

\section{FULL TEXT}

(C) 2016 The Authors. Published by ESG (www.electrochemsci.org). This article is an open access article distributed under the terms and conditions of the Creative Commons Attribution license (http://creativecommons.org/licenses/by/4.0/). 